\title{
武汉城市圈生态网络时空演变及管控分析
}

\author{
李红波, 黄 悦 ${ }^{*}$, 高艳丽 \\ 华中农业大学公共管理学院, 武汉 430070
}

\begin{abstract}
摘要:武汉城市圈正历经城乡发展转型升级和空间格局调整,生态用地受到一定挤压和切割占用,生态系统功能和景观生态格 局受到一定程度的扰动, 为贯彻生态文明建设和绿色低碳环保发展的要求,构建以生态廊道、生态节点所组成的整体城市圈的 生态网络空间体系。基于形态学空间格局方法和最小累积阻力模型构建 4 个时期 (1990、2000、2010 和 2018 年) 的生态网络,利 用景观连通性指数和重力模型对源地和廊道进行重要性评价, 并提出武汉城市圈生态网络管控的建议。结果表明: (1) 19902018 年, 武汉城市圈生态源地总体上表现为逐渐减少的趋势, 从 16 个减少为 10 个; 从空间上看, 大型源地斑块并未发生变化, 主要分布在研究区南部和北部,林地和水域是生态源地的主要组成景观,但细碎斑块大量减少对区域生态网络具有较大影响。 (2) 4 个时期研究区的生态廊道分别为 66 条、120 条、99 条和 45 条,廊道数量呈现减少的趋势; 重要廊道主要分布在研究区北 部和东南部,对南北之间的物质和能量交换具有重要作用。(3) 景观连通性南北高东西低, 中部地区受人类活动干扰综合阻力 大, 东西部生态节点较少, 物种迁移阻碍较大。(4)通过建设踏脚石、修复生态断裂点和廊道差异化保护策略以增强区域景观 连通性, 促进生物多样性保护, 提升生态网络的稳定性。“两型社会”试验区设置后武汉城市圈生态网络水平呈现优化态势, 但 生态源地之间的相互作用关系还有待增强。研究结果为城市圈未来的国土空间规划和重要生态系统保护和修复工程提供科学 参考。
\end{abstract}

关键词:生态网络; MSPA;最小累积阻力模型;景观连通性;武汉城市圈

\section{Analysis on the spatio-temporal evolution and regulation of the ecological network in Wuhan metropolitan area}

\author{
LI Hongbo, HUANG Yue* , GAO Yanli \\ School of Public Administration, Huazhong Agricultural University, Wuhan 430070, China
}

\begin{abstract}
Ecological land is being squeezed and fragmentized, and ecosystem functions and landscape ecological patterns are disturbed to some degree by transforming and upgrading of urban and rural development and spatial pattern adjustment in Wuhan metropolitan area. In order to implement the requirements of ecological civilization construction and green, lowcarbon and environmental protection development, this article constructs the ecological network space system of the whole urban circle composed of ecological corridors and ecological nodes. Based on the morphologically spatial pattern method and the minimum cumulative resistance model, the ecological network of Wuhan metropolitan area was constructed in 4 periods (1990, 2000, 2010, and 2018), and the importance of source sites and corridors was evaluated using the landscape connectivity index and the gravity model, and proposed recommendations for ecological network management and regulation. The results show that: (1) from 1990 to 2018, the ecological source areas of Wuhan metropolitan area indicated a gradual decrease, from 16 to 10 ; from a spatial point of view, the large-scale source patches, which was mainly distributed in the south and north of the study area, did not change, and forest and water were the main components of the ecological source landscape, but the large reduction of fractured patches had a large impact on the regional network. (2) There were 66,
\end{abstract}

基金项目:国家自然科学基金资助面上项目 (41871179);华中农业大学自主科技创新基金资助(2016RC014)

收稿日期:2021-03-20; 接收日期:2021-07-12

*通讯作者 Corresponding author.E-mail: 1028407741@ qq.com 
120, 99 and 45 ecological corridors in the study area in the four periods, and the number of corridors showed a decreasing trend. Important corridors were mainly distributed in the north and southeast of the study area. The exchange of matter and energy played an important role. (3) Landscape connectivity was high in the north and south, and low in the east and west. There were few ecological nodes and the large obstacles to species migration in the east and west, while high comprehensive resistance and low landscape connectivity appeared in the central region. (4) Measures are taken to enhance regional landscape connectivity, and promote biodiversity protection and the stability of the ecological network, such as the construction of stepping stones, restoration of ecological breakpoints, and differentiated protection strategies for corridors. After the development of the "two-oriented society" experimental zone, the level of the ecological network of the Wuhan metropolitan area has been optimized, but the interaction between ecological sources needs to be strengthened. The research results provide a scientific reference for the future land and space planning of the city circle.

Key Words : ecological networks; MSPA; MCR; landscape connectivity; Wuhan metropolitan area

随着我国城市化的不断推进和经济的快速发展,都市圈和城市群已成为城市化发展的新特征。城市圈作 为高度密集的经济活动区域,在区域经济协调发展过程中具有重要的地位,但人口和工业的高度密集干扰了 区域的生态环境, 造成生境质量下降, 景观破碎化加剧, 区域生态安全和生物多样性受到威胁 ${ }^{[1-3]}$ 。2018 年 《中共中央国务院关于建立更加有效的区域协调发展新机制的意见 $\rangle^{[4]}$ 指出, 建立由中心城市引领的城市群 联动发展、城市群带动区域发展新模式是未来城市化发展的新趋势。研究城市群内部生态网络的变化规律, 实现生态保护与经济发展的双赢 ${ }^{[5]}$, 对城市圈经济与生态的协调发展具有重要意义。生态网络是一种可以 将生态源地、生态廊道、生态节点进行空间有机连接的网络体系, 通过设置踏脚石和修复生态断裂点连接破碎 的斑块, 增强景观连通性, 促进源地之间的物种迁移和能量流动 ${ }^{[6-8]}$, 对生物多样性保护和生态环境可持续发 展具有重要的理论和现实意义 ${ }^{[9]}$ 。

目前, 不少学者从景观生态学角度对不同尺度的生态网络进行了研究, 在研究过程中产生了许多的模型 和方法, 其中形态学空间格局方法 (Morphological Spatial Pattern Analysis, MSPA) 和最小累积阻力 (Minimum Cumulative Resistance, MCR) 模型使用最为广泛 ${ }^{[10-12]}$ 。MSPA 方法是基于土地利用栅格数据从像元层面识别 出景观连通性高的生态区域 ${ }^{[13-14]}$, 能够根据景观的位置与形态特征篎选出具备廊道属性的桥接、支线和环道 等景观类型 ${ }^{[15-16]}$, 使得生态源地的选取更具科学性。最小累积阻力模型是基于 GIS 平台,综合地形地貌、人类 活动等多种因素模拟源地之间的最小成本路径, 该模型的关键在于生态阻力面的构建和生态源地的选择, 通 常结合景观连通性指数、重力模型、电路理论和图谱理论等方法对生态网络进行构建和优化 ${ }^{[17-20]}$ 。已有研究 从生态源地选取、阻力面影响因子指标、廊道重要性识别以及网络优化等领域进行了深入探索 ${ }^{[21-25]}$, 为本研 究提供了很好的思路借鉴。

自 2007 年武汉城市圈推行“资源节约型和环境友好型”社会建设综合配套改革试验区以来,伴随着新的 经济发展机遇的同时,城市圈五环和六环高速公路相继建设,生态用地保护压力增大,生态用地总量及分布、 生态连通性面临很大的不确定性。缓解快速城市圈建设与生态环境的矛盾, 必须把 “资源节约型、环境友好 型” 社会建设作为生态文明建设的重要目标融人到城市圈建设与发展的过程中, 需要统筹协调城市圈城乡生 态网络空间体系。《长江中游城市群发展规划 (2015)》提出, 落实武汉城市圈的生态文明建设, 要着力于打造城 市群中的“绿心” 区域, 以南部林区为核心, 构建以生态廊道、生态节点所组成的整体城市圈的绿色生态网络体 系。武汉城市圈作为国家级试验区, 是中部崛起的中坚力量, 在山水林田湖草系统治理的背景下, 建立一体化的 城市圈生态网络体系自然骨架,促进“两型社会”的建设与实施,从而创造人与自然和谐的生态城市圈。

本文以武汉城市圈为研究区,根据 4 期土地利用数据, 以“两型社会”试验区“未设置前、基本形成后” 的 两个关键节点即 2000 年和 2018 年作为参照时间, 采用 MSPA 方法识别和提取出对物种迁移和能量交换具有 重要作用的核心区景观, 选用景观连通性指数对核心区进行景观连接度评价, 将斑块重要性指数高的核心区 斑块作为生态源地。基于最小累积阻力模型模拟生态廊道构建城市圈生态网络, 最后采用重力模型对生态廊 
道结构进行评价分析,探讨 1990-2018 年武汉城市圈生态网络的演变规律及“两型社会”试验区设置前后生 态网络水平的变化情况, 并对城市圈生态网络提出管控建议, 以期为连续而完整的生态网络体系的武汉都市 圈培育、引导国土空间规划和重要生态系统保护和修复工程提供一些参考。

\section{1 研究区概况}

武汉城市圈地处湖北省东部、长江中游、汉江平原中东部, 位于 $28^{\circ} 50^{\prime}-31^{\circ} 57^{\prime} \mathrm{N}, 112^{\circ} 22^{\prime}-116^{\circ} 22^{\prime} \mathrm{E}$ 。 它是以武汉市为中心,包括周边黄冈、黄石、鄂州、孝感、咸宁、仙桃、潜江、天门 8 个城市所组成的城市群(图 1 ), 是中部崛起的重要战略支点。区内建立健全资源节约、环境保护的体制机制,着力推进资源节约型和环 境友好型社会建设,推动跨区域生态保护与开发利用,大力发展循环经济,初步形成了“一核一带三区四轴” 的城市化发展框架和“一环两翼” 的生态区域保护格局。2018 年,城市圈总面积约为 5.8 万 $\mathrm{km}^{2}$,占全省的 $31.2 \%$, 常住人口约为 3800 万人, 占全省的 $64.2 \%$,形成了优势互补、资源共享的经济发展格局。但随着城市 化的快速发展,建成区不断向外扩张,势必会挤占周围的优质耕地和生态用地,城市圈未来国土空间可持续发 展面临严峻挑战。因此有必要研究 1990-2018 年武汉城市圈的生态网络时空演变趋势,并探究“两型社会” 战略下如何构建区域协调一体的生态网络体系,为城市圈未来生态空间规划和可持续发展提供参考。

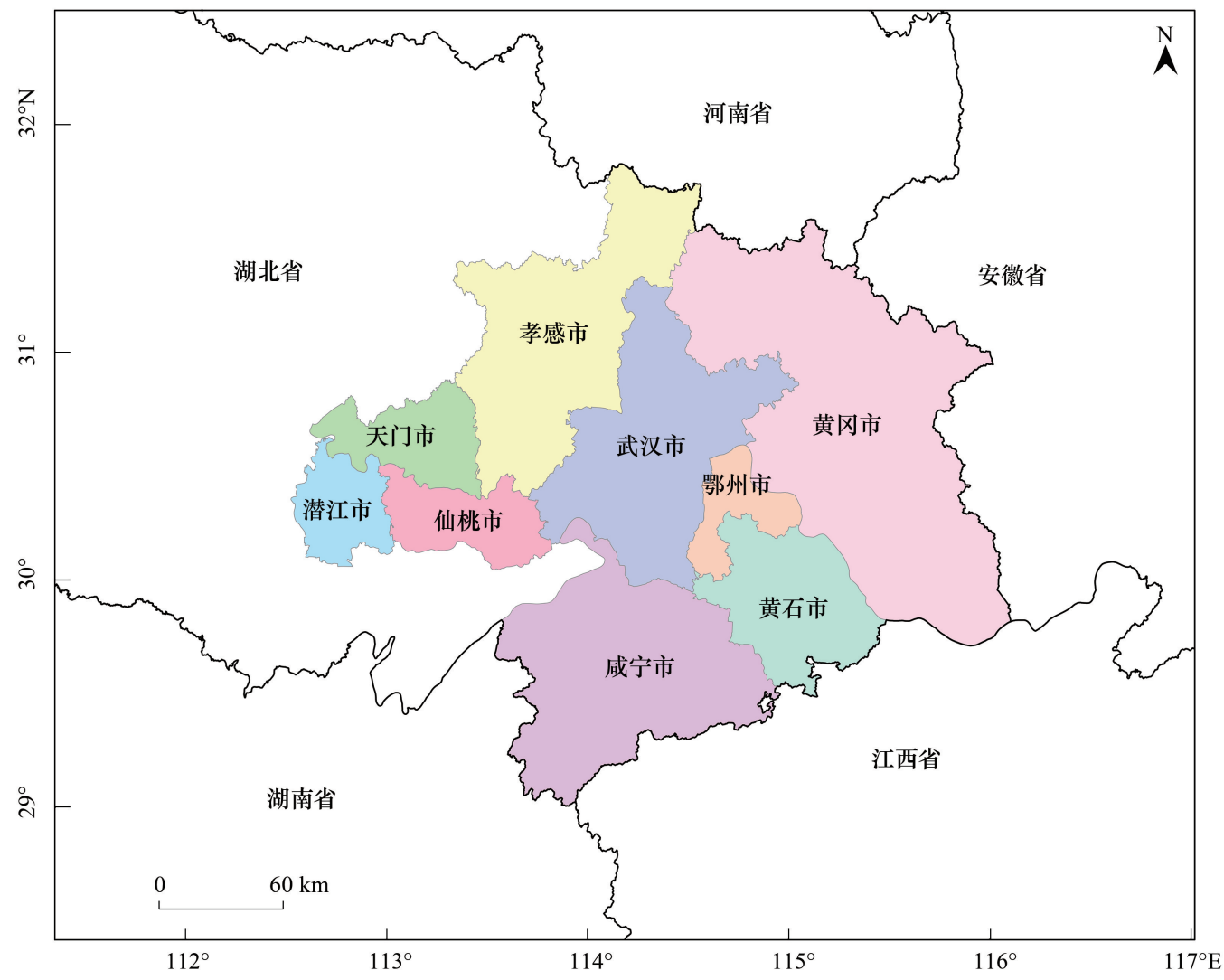

图 1 研究区位置及范围

Fig.1 Location and range of study area

\section{2 数据与研究方法}

\section{1 数据来源}

本文研究的数据包括 1990 、2000、2010、2018 年的 landsat TM/OLI 遥感影像数据、DEM 数据、道路矢量数 据, 遥感影像数据和 DEM 数据来源于地理空间数据云 (http://www.gscloud.cn/), 分辨率为 $30 \mathrm{~m}$, 道路数据来 源于 OpenStreetMap 网站 (https://www.openstreetmap.org/)。利用 ENVI 5.1 软件对 4 期遥感影像进行辐射定 
标、大气校正、镶嵌、裁剪等预处理,再采用面向对象的方法进行分类,参考《土地利用现状分类》标准( GB $/ \mathrm{T}$ 21010-2017), 并根据研究需要进行重新分类,将武汉城市圈土地利用类型划分为耕地、林地、草地、水域、建 设用地、未利用土地 6 类。结合 Google 地图和实地调研对分类结果不断进行修正,最终解译精度为 $83.7 \%$,符 合本次研究的精度要求。遥感解译得到的武汉城市圈 4 期的土地利用分类结果如图 2 所示。
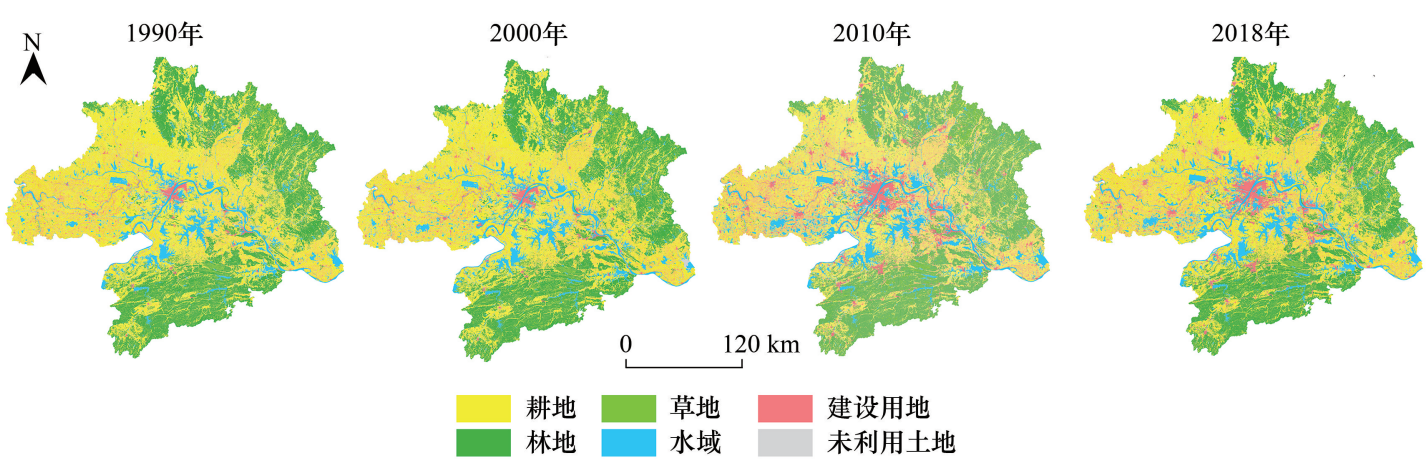

图 2 四期土地利用分类图

Fig.2 Land use classification of four periods

\section{2 研究方法}

\subsection{1 基于 MSPA 方法的景观格局分析}

形态学空间格局分析方法 (MSPA) 是 Vogt 等学者提出的能够比较精确的对栅格图像进行空间格局功能 类型划分的一种方法 ${ }^{[26]}$, 能识别出像元层面上对区域景观连通性有重要作用的斑块 ${ }^{[27]}$, 为生态源地和生态 廊道的选择提供更加科学的依据 ${ }^{[25,28]}$ 。根据 MSPA 方法的需要, 利用 ArcGIS 将遥感解译后的土地利用分类 数据转换为 $30 \mathrm{~m} \times 30 \mathrm{~m}$ 的二值 TIFF 栅格数据。MSPA 方法的研究对象分为前景和背景两类, 将林地、草地、 水域作为前景数据,耕地、建设用地和未利用土地作为背景数据。运用 GuidosToolbox 软件, 采用八邻域分析 方法进行景观格局分析, 在进行骨架抽取、腐蚀运算等一系列的数学计算后,获得了具有不同功能的 7 种景观 类型 (表 1), 并统计 MSPA 分析结果。其中核心区一般是前景图像中面积较大的生态斑块,可以为物种栖息 与迁移提供良好的基底, 具有较高的生态服务价值, 可以从中选取生态源地。

表 1 MSPA 景观类型及含义

Table 1 Landscape types and meanings of MSPA

\begin{tabular}{ll}
\hline 景观类型 & 生态学含义 \\
Landscape types & Ecological meaning \\
\hline 核心区 Core & 面积较大的生境斑块,对物种迁移与栖息具有重要影响,一般作为生态网络的源地 \\
环道区 Loop & 连接同一核心区的生态廊道,是核心区内部物质能量流动的通道 \\
桥接区 Bridge & 连接核心区的狭长斑块,是相邻核心区之间物质与能量流动的重要通道,对物种迁移和能量流动具有重要意义 \\
边缘区 Edge & 核心区与背景区域的过渡区域,具有边缘效应 \\
岛状斑块 Islet & 和外部不相连的孤立的、破碎的小斑块,连接度较低,进行物质能量传递的可能性比较小 \\
支线 Branch & 只有一端与桥接区、环道区、边缘区或孔隙相连 \\
孔隙 Perforation & 核心区的内部边缘区域,是核心区到背景区域的过渡地带 \\
\hline
\end{tabular}

MSPA:形态学空间格局方法 Morphological Spatial Pattern Analysis

\subsection{2 景观连通性评价}

景观连通性是指景观要素间进行能量、物质交换和迁移的生态过程对斑块间运动速率产生的综合效 应 ${ }^{[29]}$, 对维持生物多样性和生态环境稳定发挥重要作用 ${ }^{[30]}$ 。为选取研究所需的生态源地, 采用整体连通性 指数 IIC、可能连通性指数 PC 和斑块重要性指数 $\mathrm{dPC}$, 来测算研究区核心斑块间的连接度水平。斑块连接度 指数越高, 说明重要性越大, 最后根据斑块重要性指数来选择生态源地。 


$$
\begin{gathered}
\mathrm{IIC}=\frac{\sum_{i=1}^{n} \sum_{j=1}^{n} \frac{a_{i} a_{j}}{1+n l_{i j}}}{A_{L}^{2}} \\
P C=\frac{\sum_{i=1}^{n} \sum_{j=1}^{n} a_{i} \times a_{j} \times p_{i j}^{*}}{A_{L}^{2}} \\
\mathrm{dPC}=\frac{P C-P C_{\text {remove }}}{P C} \times 100 \%
\end{gathered}
$$

式中, $i \neq j ; n$ 表示核心区斑块数; $a_{i}$ 和 $a_{j}$ 分别表示斑块 $i$ 和 $j$ 的面积; $n l_{i j}$ 表示斑块 $i$ 和斑块 $j$ 之间的连接数; $A_{L}^{2}$ 表示研究区景观的总面积; $p_{i j}^{*}$ 表示斑块 $i$ 和斑块 $j$ 之间所有路径概率的乘积最大值, PC 的取值范围为 0 到 $1, \mathrm{PC}$ 值越大, 斑块间连通性越高; $P C$ 表示去除某一斑块后剩余斑块的可能连接度指数。

源地一般都是具有高连通性的大型生物栖息地或自然保护区, 根据研究区实际情况,本文选择面积大于 $100 \mathrm{~km}^{2}$ 的核心区斑块作为景观连通性评价对象 ${ }^{[9]}$ 。运用 Conefor 2.6 软件, 参考以往研究 ${ }^{[31-33]}$ 和研究区尺度 范围, 设置连通距离阈值为 $1500 \mathrm{~m}$, 连通概率为 0.5 , 对研究区面积最大的 40 个核心区斑块进行景观连通性 评价,并将斑块重要性指数 $(\mathrm{dPC})$ 大于 1.2 的核心区斑块作为物种栖息与发展的源地。

\subsection{3 最小累积阻力模型}

最小累积阻力模型 (Minimum Cumulative Resistance, MCR) 是模拟生态廊道的常用方法, 可以计算出源与 目标之间的最小累积阻力距离来确定物种迁移的最佳路径 ${ }^{[34-35]}$ 。 MCR 模型最早应用于物种迁移与扩散的研 究, 俞孔坚等 ${ }^{[36]}$ 学者率先将其引入国内, 具有构建简易和要素可拓等特点, 可以有效避免外界的干扰, 从而模 拟物种运动的趋向性和可能性。

$$
\operatorname{MCR}=f_{\min } \sum_{j=n}^{i=m}\left(D_{i j} \times R_{i}\right)
$$

式中, $f_{\min }$ 表示最小累积阻力值, $D_{i j}$ 为生态源 $j$ 到景观单元 $i$ 的空间距离; $R_{i}$ 则为景观单元 $i$ 对某运动的阻力 系数。

源地的选取和生态阻力面的构建是 MCR 模型运行的核心要素,因此必须选取合适的指标来构建综合阻 力面体系。阻力面的构建需要综合考虑自然条件和人为干扰等因素,参考相关文献 ${ }^{[9,21-24]}$, 鉴于研究区的实 际情况和数据的获取程度, 从地形、景观类型、人类活动等方面选取了高程、坡度、景观类型、距道路的距离、距 建设用地的距离等 5 个指标来构建综合阻力指标体系 (表 2)。通过咨询专家意见和参考相关研究 ${ }^{[17-18]}$, 确定 各阻力因子的分级和分值, 分值越大, 阻碍物种迁移扩散的作用力越大, 然后根据层次分析法确定各阻力因子 权重。基于 ArcGIS 10.2 软件对土地利用景观类型进行属性赋值, 转成栅格数据, 将景观阻力评价因子进行综 合景观阻力评价, 获得综合生态阻力面, 从而得到 MCR 模型的成本数据。

基于 ArcGIS 软件平台,采用距离分析模块中的 Cost Weighted 工具, 根据综合阻力面和生态源地计算每个 源地的累积成本面, 再运用 Distance 中的 Shortest Path 工具, 生成目标源地到其他源地斑块的最小累积阻力路 径, 从而得到由潜在生态廊道和生态源地组成的研究区生态网络。

\subsection{4 重力模型}

生态源地之间的相互作用强度可用来定量分析生态廊道的有效性和重要性 ${ }^{[37]}$ 。重力模型能够对空间中 各个对象彼此之间的作用强度和依存关系进行定量描述，一般用来分析在地理空间中研究对象的相互联 系 ${ }^{[38-39]}$ 。采用重力模型计算各个斑块之间彼此的相互作用强度, 构建生态源地斑块之间的互相作用矩阵, 从 而识别和提取重要生态廊道。重力模型的计算公式如下:

$$
G_{i j}=\frac{N_{i} N_{j}}{D_{i j}^{2}}=\frac{\left[\frac{1}{P_{i}} \times \ln \left(S_{i}\right)\right]\left[\frac{1}{P_{j}} \times \ln \left(S_{j}\right)\right]}{\left(\frac{L_{i j}}{L_{\max }}\right)^{2}}=\frac{L_{\max }^{2} \ln \left(S_{i} S_{j}\right)}{L_{i j}^{2} P_{i} P_{j}}
$$


式中, $G_{i j}$ 是源地斑块 $i$ 和斑块 $j$ 之间的相互作用力; $N_{i}$ 和 $N_{j}$ 为斑块 $i$ 和斑块 $j$ 的权重值; $D_{i j}$ 是两斑块之间标准化 的廊道阻力值; $P_{i}$ 表示斑块 $i$ 的阻力值; $P_{j}$ 为斑块 $j$ 的阻力值; $S_{i}$ 和 $S_{j}$ 为两斑块的面积; $L_{i j}$ 表示斑块 $i$ 到斑块 $j$ 之 间的廊道累积阻力值; $L_{\text {max }}$ 指网络中所有廊道阻力的最大值。

表 2 阻力因子分级、权重与赋值表

Table 2 Resistance factor classification, weight and assignment table

\begin{tabular}{|c|c|c|c|c|c|c|c|}
\hline $\begin{array}{l}\text { 阻力因子 } \\
\text { Resistance factor }\end{array}$ & $\begin{array}{c}\text { 权重 } \\
\text { Weight }\end{array}$ & $\begin{array}{c}\text { 分级指标 } \\
\text { Grading } \\
\text { index }\end{array}$ & $\begin{array}{c}\text { 阻力值 } \\
\text { Resistance } \\
\text { value }\end{array}$ & $\begin{array}{l}\text { 阻力因子 } \\
\text { Resistance factor }\end{array}$ & $\begin{array}{c}\text { 权重 } \\
\text { Weight }\end{array}$ & $\begin{array}{c}\text { 分级指标 } \\
\text { Grading } \\
\text { index }\end{array}$ & $\begin{array}{c}\text { 阻力值 } \\
\text { Resistance } \\
\text { value }\end{array}$ \\
\hline 高程 & 0.14 & $<50$ & 1 & 距道路距离 & 0.29 & $<500$ & 9 \\
\hline \multirow[t]{4}{*}{ Elevation/m } & & $50-150$ & 3 & Distance from road $/ \mathrm{m}$ & & $500-1500$ & 7 \\
\hline & & $150-250$ & 5 & & & $1500-2500$ & 5 \\
\hline & & $250-350$ & 7 & & & $2500-3500$ & 3 \\
\hline & & $>350$ & 9 & & & $>3500$ & 1 \\
\hline \multirow[t]{5}{*}{ 坡度 Slope $/\left({ }^{\circ}\right)$} & 0.17 & $<3$ & 1 & 距建设用地距离 & 0.18 & $<500$ & 9 \\
\hline & & $3-8$ & 3 & Distance to construction land $/ \mathrm{m}$ & & $500-1500$ & 7 \\
\hline & & $8-15$ & 5 & & & $1500-2500$ & 5 \\
\hline & & $15-25$ & 7 & & & $2500-3500$ & 3 \\
\hline & & $>25$ & 9 & & & $>3500$ & 1 \\
\hline 景观类型 & 0.22 & 林地 & 1 & & & & \\
\hline \multirow[t]{4}{*}{ Landscape types } & & 耕地、草地 & 3 & & & & \\
\hline & & 未利用土地 & 5 & & & & \\
\hline & & 水域 & 7 & & & & \\
\hline & & 建设用地 & 9 & & & & \\
\hline
\end{tabular}

\section{3 结果与分析}

\section{1 基于 MSPA 的景观格局分析}

由表 3、图 3 可知, 1990、2000、2010 和 2018 年 MSPA 分析的前景数据面积分别为 24164.35 、24672.23、 $25303.58 、 25167.52 \mathrm{~km}^{2}$, 约占研究区总面积的 $40 \%$ 。在前景数据中,核心区景观面积最大,分别占前景总面积 的 $87.4 \% 、 87.14 \% 、 86.95 \% 、 86.66 \%$, 其主要分布在研究区的南部及东北部,中部和西部比较稀少,集中分布在 东北部。1990、2000、2010 和 2018 年维持景观连通性的桥接区面积分别为 $55.34 、 55 、 57.82 、 62.55 \mathrm{~km}^{2}$, 仅占前 景面积的 $0.2 \%$ 左右,面积较少,说明核心斑块之间的联系不够密切。作为核心区与外面背景区域的过渡斑 块, 边缘区占前景面积的 $8 \%$ 以上, 具有一定的边缘效应。环道区是核心区内部迁移和物质流动的通道, 占前
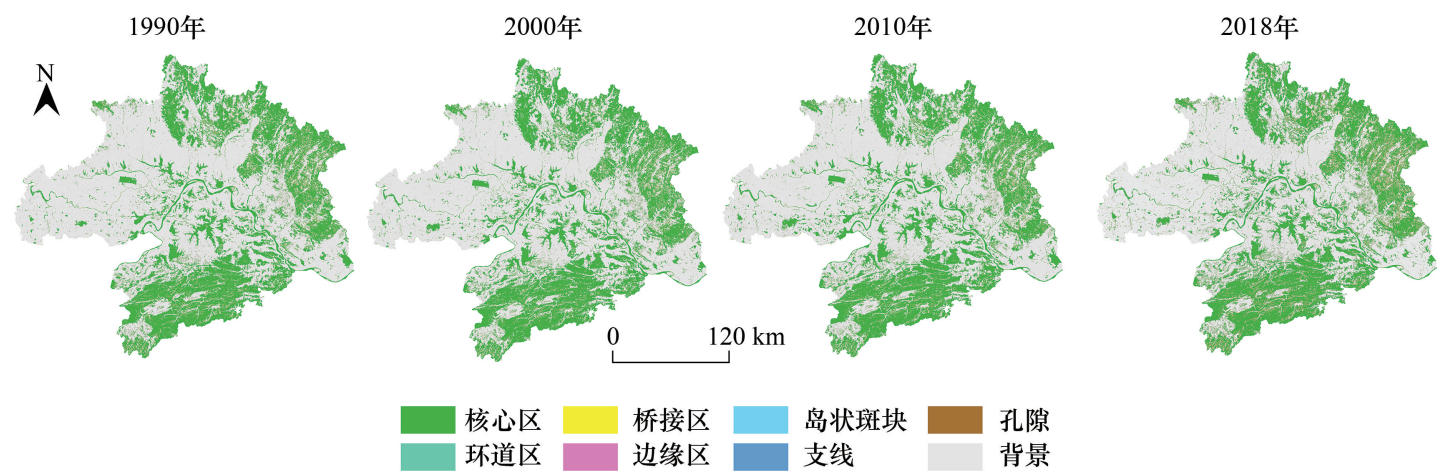

图 3 四期景观格局功能类型

Fig.3 Functional types of landscape pattern in the fourth stage 
景面积的 $0.04 \%$, 且从 1990 年到 2018 年仅增长了 $0.01 \%$ 。岛状斑块面积较小, 2018 年面积略有增长, 占前景 面积的 $0.03 \%$, 主要散布在核心区的中部, 是孤立存在的景观斑块, 可以考虑作为生物的踏脚石。孔隙是核心 区域的内部边缘,和边缘区一样具有边缘效应, 1990-2018 年孔隙的面积在逐渐减少,说明核心区内部边缘 效应在减弱。支线具有一定的连通作用，只与核心区、桥接区、环道区等的一端相连, 1990-2018 年, 支线的 面积在逐渐增加, 表明生态连接通道在不断增长。

表 3 MSPA 分类统计表

Table 3 Classification Statistical Table of MSPA

\begin{tabular}{|c|c|c|c|c|}
\hline $\begin{array}{l}\text { 景观类型 } \\
\text { Landscape types }\end{array}$ & $\begin{array}{l}\text { 年份 } \\
\text { Year }\end{array}$ & $\begin{array}{c}\text { 面积 } \\
\text { Area/ } \mathrm{km}^{2}\end{array}$ & $\begin{array}{c}\text { 占前景面积比例 } \\
\text { Percent in foreground area } / \%\end{array}$ & $\begin{array}{c}\text { 占总面积比例 } \\
\text { Percent in total area/\% }\end{array}$ \\
\hline \multirow[t]{4}{*}{ 核心区 Core } & 1990 & 21424.92 & 87.04 & 36.94 \\
\hline & 2000 & 21498.65 & 87.14 & 37.07 \\
\hline & 2010 & 22001.72 & 86.95 & 37.93 \\
\hline & 2018 & 21810.35 & 86.66 & 37.60 \\
\hline \multirow[t]{4}{*}{ 环道区 Loop } & 1990 & 10.21 & 0.04 & 0.02 \\
\hline & 2000 & 10.28 & 0.04 & 0.02 \\
\hline & 2010 & 10.90 & 0.04 & 0.02 \\
\hline & 2018 & 12.27 & 0.05 & 0.02 \\
\hline \multirow[t]{4}{*}{ 桥接区 Bridge } & 1990 & 55.34 & 0.22 & 0.10 \\
\hline & 2000 & 55.00 & 0.22 & 0.09 \\
\hline & 2010 & 57.82 & 0.23 & 0.10 \\
\hline & 2018 & 62.55 & 0.25 & 0.11 \\
\hline \multirow[t]{4}{*}{ 边缘区 Edge } & 1990 & 1990.14 & 8.09 & 3.43 \\
\hline & 2000 & 1985.03 & 8.05 & 3.42 \\
\hline & 2010 & 2114.41 & 8.36 & 3.65 \\
\hline & 2018 & 2257.64 & 8.97 & 3.89 \\
\hline \multirow[t]{4}{*}{ 岛状斑块 Islet } & 1990 & 3.13 & 0.01 & 0.01 \\
\hline & 2000 & 2.97 & 0.01 & 0.01 \\
\hline & 2010 & 4.16 & 0.02 & 0.01 \\
\hline & 2018 & 6.59 & 0.03 & 0.01 \\
\hline \multirow[t]{4}{*}{ 支线 Branch } & 1990 & 173.40 & 0.70 & 0.30 \\
\hline & 2000 & 173.99 & 0.71 & 0.30 \\
\hline & 2010 & 190.04 & 0.75 & 0.33 \\
\hline & 2018 & 202.03 & 0.80 & 0.35 \\
\hline \multirow[t]{4}{*}{ 孔隙 Perforation } & 1990 & 957.21 & 3.89 & 1.65 \\
\hline & 2000 & 946.31 & 3.84 & 1.63 \\
\hline & 2010 & 924.53 & 3.65 & 1.59 \\
\hline & 2018 & 816.09 & 3.24 & 1.41 \\
\hline
\end{tabular}

3.2 生态源地变化分析

基于景观连通性指数计算结果,探究“两型社会”试验区设置前后城市圈生态源地变化情况。根据景观 连通性评价结果, 从核心区中选取斑块重要性指数较大的斑块作为生态源地 (图 4), 其地类主要是林地、草地 和水域。1990-2018 年 4 个时期的生态源地个数分别为 $12 、 16 、 14 、 10$, 可以看出生态源地在逐渐减少。随着 经济的发展,生态环境遭到一定程度的破坏, 加上国土空间综合整治对破碎斑块的整合,生态源地的数量呈现 减少的趋势。1990 年生态源地较少的原因主要是 1980 年开始实行家庭联产承包责任制, 大量开垦耕地, 部 分地区滥砍滥伐、围湖造田严重, 林地和水域面积锐减,生态源地数量因而较少。1998 年长江特大洪涝灾害 之后,政府提出了退耕还湖的政策,水域景观得到一定改善,因而表现为 1990-2000 年大型生境斑块有一定 
程度的增加。2001 年开始在武汉城市圈试点退耕还林, 使得林地面积逐渐增加,生态景观慢慢趋向稳定。 2005 年提出社会主义新农村建设,农业景观得到改善,但“村村通” 等工程建设也使得建设用地逐渐增加, 因 此总体上生态源地略有减少。到 2018 年,经过试验区建设向纵深推进,基本形成稳定的规模,生态环境得到 一定的改善。
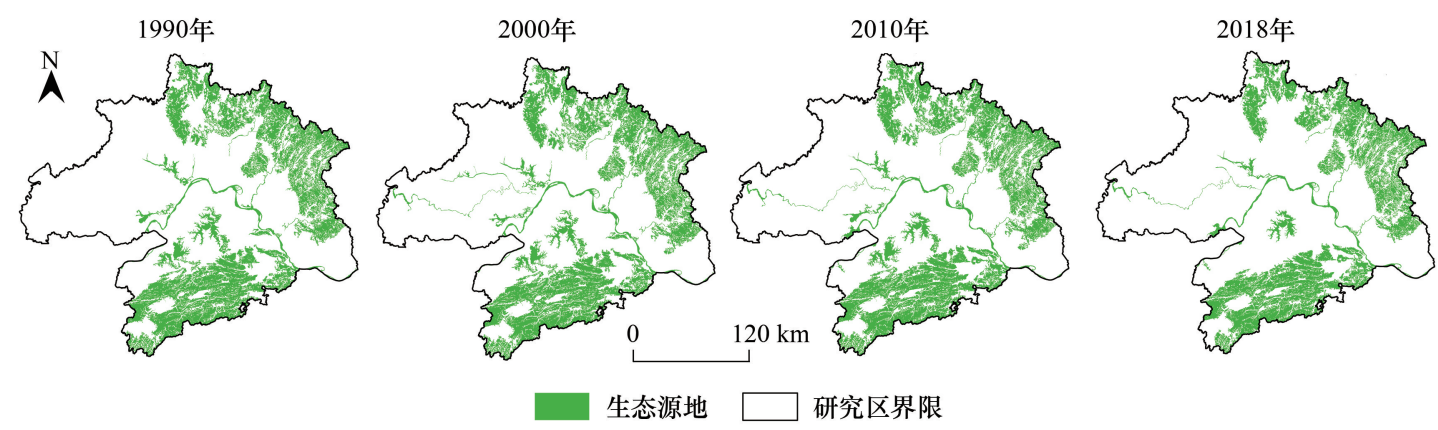

图 4 生态源地结果

Fig.4 Results of ecological sources

\section{3 生态网络构建}

\subsection{1 生态阻力分析}

综合自然与人为因素, 通过对影响因子叠加分析, 得到武汉城市圈四期的综合阻力面 (图 5)。由图 5 可 知, 研究区西部和南北部阻力较小, 部分地区阻力较高, 例如武汉市的中部、鄂州市的西南部等地区。高阻力 区域主要位于研究区的中部和东部,包括武汉市、鄂州市、黄冈市、孝感市及咸宁市的北部区域,这是由于建设 用地和交通路网分布密集对这些地区的影响较大, 南北低,中部高的阻力分布, 影响区域之间的物种迁移和能 量流动, 导致东西部之间的连通性较差。从时空演变上看, 从 1990-2018 年, 高阻力地区总体呈现波动增长 趋势。1990-2000 年, 大力发展生产力, 开垦耕地和围湖造田对生态环境的影响较大, 导致高阻力地区有所 增加;2000-2010 年,实施“两型社会”试验区后,发展经济的同时也注重环境保护,高阻力地区在逐渐减少; 2010-2018 年, “两型社会”试验区基本形成后, 高阻力地区主要集中在研究区中部经济发达、人口密集的 区域。
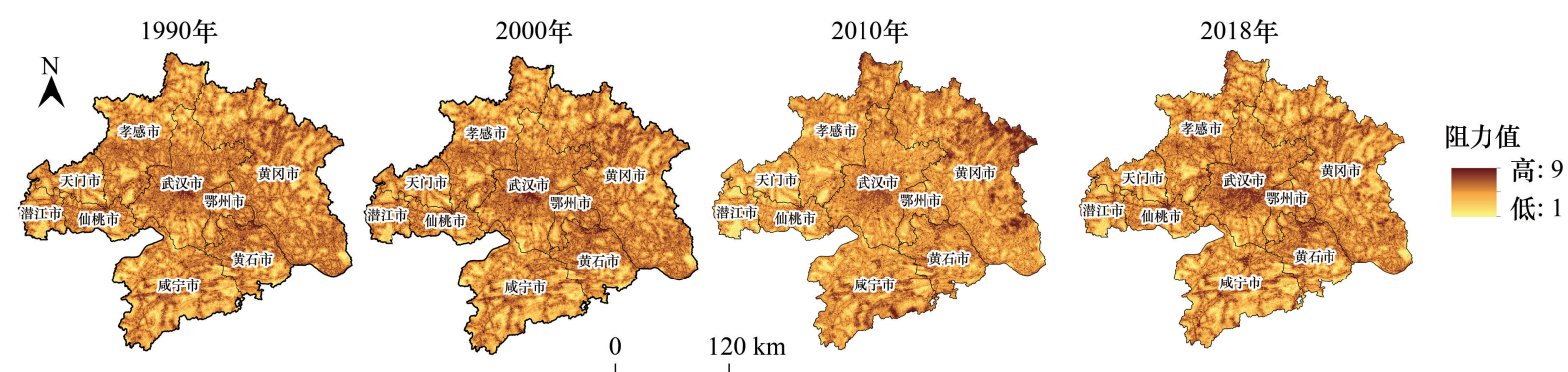

图 5 综合阻力面

Fig.5 Comprehensive resistance surface

\subsection{2 生态廊道模拟}

利用最小成本路径来模拟生态廊道, 基于综合成本阻力面, 生成源地之间的最小耗费路径, 来模拟物种迁 移的轨迹。由表 4、图 6 可知, 1990 年生态廊道共有 66 条, 北部廊道比较稀疏, 而南部的廊道分布则比较密 集, 更利于物种之间物质与能量的交换; 2000 年生态廊道共有 120 条,廊道数量较 1990 年有一定的增长, 廊 道交点为 449 个,廊道之间的交叉现象比较密集, 内部景观连通性较强; 2010 年生态廊道共有 91 条,生态廊 
道与 2000 年相比有所减少,但廊道的延伸性有所增强,生态廊道呈现条带状分布, 延伸到研究区南北部边缘, 使得武汉城市圈南北景观连通性增强;2018 年生态廊道共有 45 条,生态廊道由原来的南北条带式分布转变 为向东西部延伸,空间上较为分散,廊道交点为 114 个,内部交叉现象减少,但廊道连接的范围向四周扩散,使 得研究区东西方向的物种迁移活动更加便捷。1990-2018 年,生态廊道的数量在逐渐减少,一是由于城市扩 张和建成区面积不断增加, 使得生态源地和生态节点减少, 连接节点的廊道相应减少; 二是交通路网和旅游景 点的建设,物种迁移的阻力增大,使得部分廊道发生断裂,可能会面临面积减少甚至消失的问题。

表 4 生态廊道与生态节点数量统计

Table 4 Statistics on the number of ecological corridors and ecological nodes

\begin{tabular}{cccc||cccc}
\hline \multirow{2}{*}{$\begin{array}{c}\text { 年份 } \\
\text { Year }\end{array}$} & $\begin{array}{c}\text { 生态廊道/条 } \\
\text { Ecological } \\
\text { corridor }\end{array}$ & $\begin{array}{c}\text { 生态节点/个 } \\
\text { Ecological } \\
\text { node }\end{array}$ & $\begin{array}{c}\text { 廊道交点/个 } \\
\text { Corridor } \\
\text { intersection }\end{array}$ & $\begin{array}{c}\text { 年份 } \\
\text { Year }\end{array}$ & $\begin{array}{c}\text { 生态廊道/条 } \\
\text { Ecological } \\
\text { corridor }\end{array}$ & $\begin{array}{c}\text { 生态节点/个 } \\
\text { Ecological } \\
\text { node }\end{array}$ & $\begin{array}{c}\text { 廊道交点/个 } \\
\text { Corridor } \\
\text { intersection }\end{array}$ \\
\hline 1990 & 66 & 12 & 193 & 2010 & 91 & 14 & 407 \\
2000 & 120 & 16 & 449 & 2018 & 45 & 10 & 114 \\
\hline
\end{tabular}

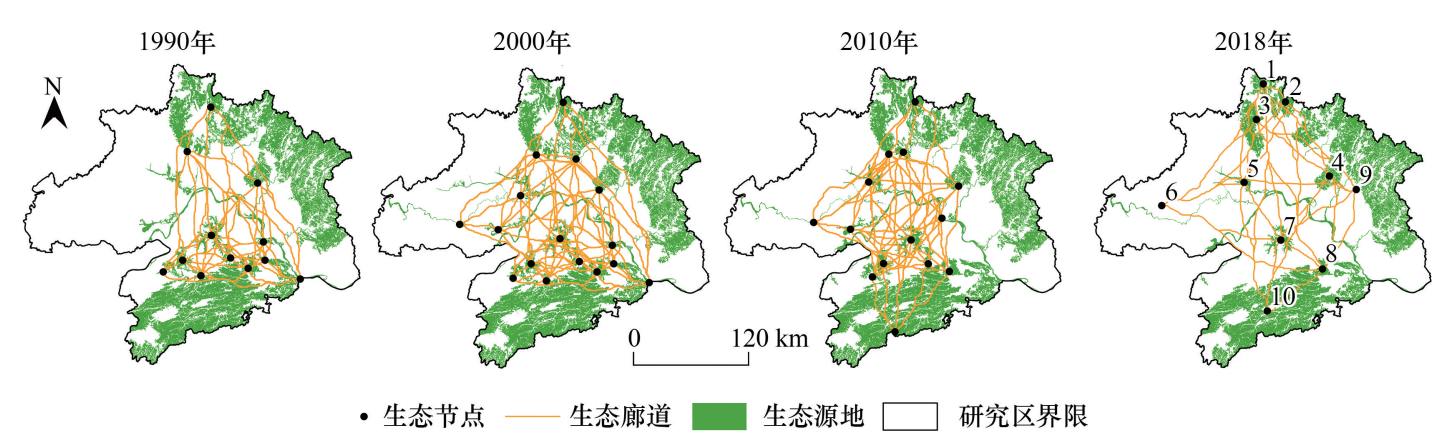

图 6 研究区生态网络

Fig.6 Ecological network of study area

\subsection{3 重力模型结果分析}

基于重力模型, 构建生态源地之间的相互作用矩阵, 根据相互作用力的大小来判定廊道的重要性,源地与 其他源地之间的相互作用力越大, 源地上物种迁移和流动的阻力越小, 则生态廊道的重要性越高。根据生态 源地的大小, 将相互作用力大于 100 的生态廊道作为重要廊道, 其他作用值低于 100 的作为一般廊道。武汉 城市圈的生态廊道分级极线图如图 7 所示。结果表明, 1990 年武汉城市圈共有生态廊道 66 条, 其中重要廊 道有 32 条,一般廊道有 34 条; 2000 年共有生态廊道 120 条,其中重要廊道有 50 条,一般廊道有 70 条; 2010 年共有生态廊道 91 条,其中重要廊道有 41 条,一般廊道有 50 条;2018 年共有生态廊道 45 条,其中重要廊道 有 17 条,一般廊道有 28 条。重要廊道一般是面积较大且景观连通性较好的区域,主要分布在研究区的北部 和南部, 连接北部的大别山林区和南部的九宫山等山群。这些重要生态廊道是物种迁移与能量交换的主要通 道, 受人类活动干扰较小, 也是物种迁移阻力最小的便捷路径。一般廊道数量较多, 分布广泛, 距离人类活动 区域较近, 受人类活动干扰频繁, 斑块面积较小, 不适宜大范围的物种迁移活动。

\section{4 生态网络管控与引导}

纵观 1990-2018 年近 30 年武汉城市圈生态网络的演变可知,引起生态网络格局变化的主要原因在于生 态源地,生态源地的数量和面积的变化对生态节点和生态廊道有很大的影响, 源地的缺失势必会破坏原有的 生态网络结构。对一定区域范围的生态网络进行网络管控需要对该区域网络结构及构成要素具有准确的认 识, 制定针对性的保护策略, 维护整体生态功能, 促进生态系统健康可持续发展。踏脚石斑块可以为物种迁移 提供一个短暂的栖息地, 有利于提高物种迁移的成功性和生物的存活率。本研究基于生态节点和生态廊道, 

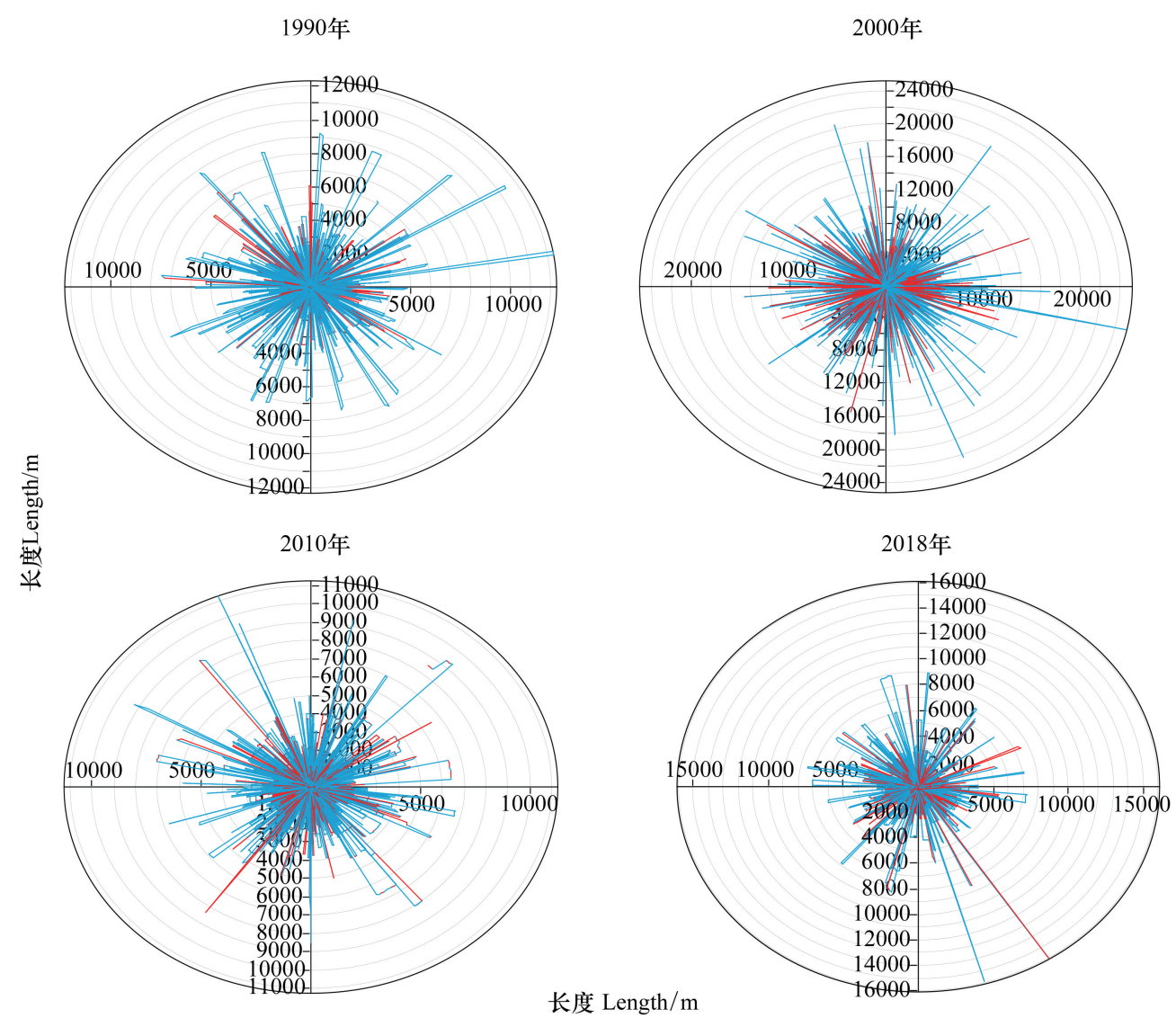

图 7 生态廊道极线图

Fig.7 Polar view of ecological corridor

结合道路交叉点, 加上廊道之间的交汇点, 确定了 23 个踏脚石, 识别了 25 个生态断裂点 (图 8 )。鉴于此, 本 文提出对研究区生态网络管控的建议:
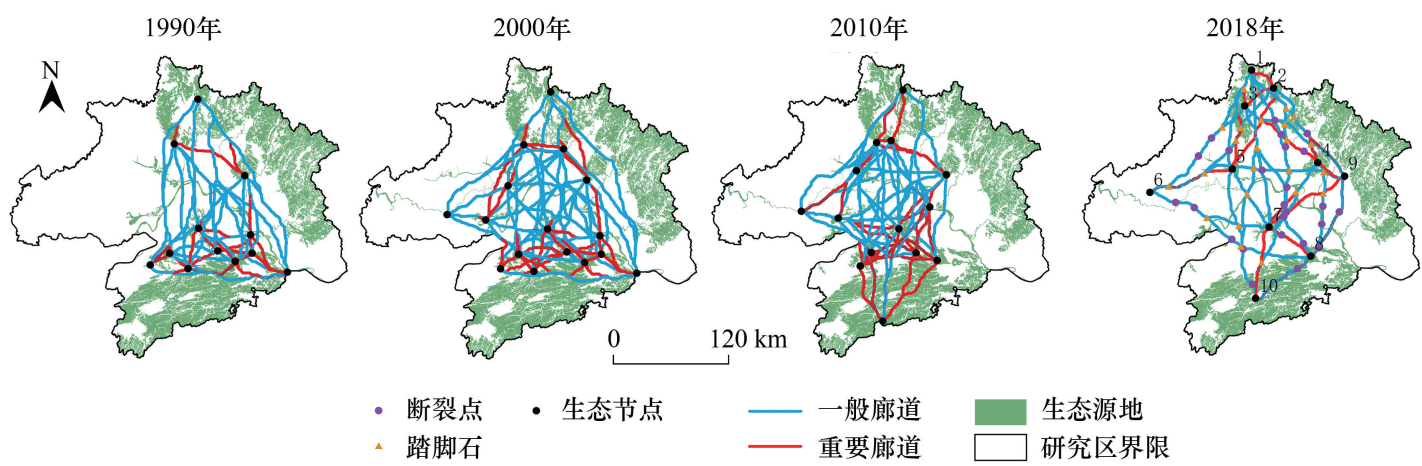

图 8 生态网络管控优化

Fig.8 Control and optimization of ecological network

(1) 修复生态断裂点, 加强景观连通性。道路与生态廊道相交处是生态廊道容易断裂的区域, 对景观功 能造成影响, 因此在建设道路工程时建议设置天桥或隧道等生物通道, 有利于提高物种迁移的存活率, 保证正 常的物质能量流通。研究区的生态断裂点主要分布在中部和东北部路网比较密集的区域, 应当加强廊道周边 的绿化建设,控制建设用地的扩张范围,为未来生态廊道规划预留一定的生态建设空间。 
(2) 建设踏脚石, 增强廊道的稳定性。受人为活动和廊道自身特性的影响, 较长的生态廊道更容易受到 外在环境的干扰。研究区东西部生态源地之间的景观连通性较差, 中部人为干扰强度和生态阻力较大, 中部 区域的廊道受人类活动影响频繁,生态阻力较大, 且南北方向的部分生态廊道距离较远, 容易发生断裂, 因而 需要建设踏脚石斑块, 以增强生态廊道的稳定性。

(3) 生态廊道差异化保护, 提升生态网络服务水平。根据廊道重要性评价结果, 对重要廊道和一般廊道 进行差异化保护。武汉城市圈的生态源地主要是林地、草地和水域等景观类型,重要廊道连接的是自然保护 区和大型森林公园等生态功能较高的区域, 需要对这类廊道进行优先保护。一般廊道数量多分布较为分散, 需要对其进行缓冲区建设,通过建设生态绿化带、生态功能区减少人为活动的干扰, 更好的发挥区域生态网络 的生态服务功能。

\section{4 结论与讨论}

本研究以山水林田湖草是一个生命共同体为理念, 以生态本底和自然资源禀赋为基础, 遵循生态系统内 在机理, 构建武汉城市圈城乡生态网络空间体系, 关注生态网络风险应对, 切实增强生态系统稳定性。基于 MSPA 方法和最小累积阻力模型, 从生态源地识别、景观连通性评价以及生态廊道模拟等方面构建多时期的 武汉城市圈生态网络, 探讨城市圈生态网络的演变规律, 并对当前生态网络存在的问题进行管控, 建成生态保 护的整体性引导, 形成圈内系统协调、功能完善的生态保护格局, 通过对网络相互作用机理的定量研究来理解 城市圈生态网络系统的整体性和复杂性形成的机制。

研究结果表明:生态源地主要分布在研究区南部、北部和东部,林地、草地、水域是生态源地的主要组成部 分, 不同源地之间的相互作用力差异显著; 综合阻力南北低,东部中部高西部低, 东西部的景观联系有待加强; 景观连通性南北高东西低, 中部受人类活动干扰大连通度较低; 基于最小累积阻力模型所提取的生态廊道加 强了南北部之间的联系, 但东西部的景观联系较弱; 生态廊道的主要组成景观是耕地和林地, 整体生态连接度 较好, 基于重力模型计算生态源地之间的相互作用力可识别出重要廊道和斑块, 重要廊道占生态廊道总数的 一半左右, 主要分布在研究区北部和东南部; 通过修复生态断裂点、建设踏脚石和生态廊道差异化保护能够提 升城市圈生态网络的稳定性, 更好的发挥生态系统的服务功能。

针对生态廊道过长和水域、路网阻隔等问题,科学配置保护和修复、自然和人工、生物和工程等措施, 推进 一体化生态保护和修复。应用 “斑块一廊道一基底” 模式构建城乡生态网络, 将城市圈建设镶嵌在自然生态 系统的基底上,优化生态廊道, 提升保护环境、稳定生态的功能,引导圈内国土空间规划与建设。

此外, 本文在选取生态源地时, 将生态敏感性较高, 以发挥重要生态服务功能为主的林地、草地、水域作为 提取生态源地的核心区, 由于武汉城市圈农田田块规模小, 沟渠较多, 因而未考虑具有自然生态功能的农田, 但不同生态本底的核心区玟块存在差异, 研究结果可能与实际情况存在细微差别。

利用最小累积阻力模型模拟潜在生态廊道, 阻力面评价指标的选取对生态网络的构建具有重要影响。目 前有关生态阻力面的设置还未有一个统一的标准, 由于缺乏详细的研究数据, 并未考虑不同物种的生活特性 和居民点分布等因素对阻力面构建的影响。后续有待进一步加强对生态网络构建与管控的深人研究, 以拓宽 国土空间生态保护修复的手段。

\section{参考文献 ( References) :}

[ 1 ] 胡炳旭, 汪东川, 王志恒, 汪翡翠, 刘金雅, 孙志超, 陈俊合. 京津冀城市群生态网络构建与优化. 生态学报, 2018, 38(12): 4383-4392.

[2] 侯宏冰, 郭红琼, 于强, 龙芉芉, 裴燕如, 岳德鹏. 鄂尔多斯景观格局演变与景观生态网络优化研究. 农业机械学报, 2020, 51 (10): 205-212, 242.

[ 3 ] 蒙吉军, 王晓东, 尤南山, 朱利凯. 黑河中游生态用地景观连接性动态变化及距离阈值. 应用生态学报, 2016, 27(6): $1715-1726$.

[ 4 ] 中共中央 国务院关于建立更加有效的区域协调发展新机制的意见. 中华人民共和国国务院公报, 2018, (35): 11- 17.

[ 5 ] 彭建, 汪安, 刘炎序, 马晶, 吴健生. 城市生态用地需求测算研究进展与展望. 地理学报, 2015, 70(2): 333-346.

[ 6 ] 王戈, 于强, Yang D, 张启斌, 岳德鹏, 刘建华. 包头市层级生态网络构建方法研究. 农业机械学报, 2019, 50(9): 235-242, 207. 
[ 7 ] Pili S, Serra P, Salvati L. Landscape and the city: Agro-forest systems, land fragmentation and the ecological network in Rome, Italy. Urban Forestry \& Urban Greening, 2019, 41: 230-237.

[ 8 ] Long C, De Vries S, Venema K. Polysaccharide source altered ecological network, functional profile, and short-chain fatty acid production in a porcine gut microbiota. Beneficial Microbes, 2020, 11(6) : 591-610.

[ 9 ] 胡其玉，陈松林. 基于生态系统服务供需的厦漳泉地区生态网络空间优化. 自然资源学报，2021，36(2)：342-355.

[10］杨志广, 蒋志云, 郭程轩, 杨晓晶, 许晓君, 李潇, 胡中民, 周厚云. 基于形态空间格局分析和最小累积阻力模型的广州市生态网络构 建. 应用生态学报, 2018, 29(10): 3367-3376.

[11] 刘世梁, 侯笑云, 尹艺洁, 成方妍, 张月秋, 董世鬼. 景观生态网络研究进展. 生态学报, 2017, 37(12): 3947-3956.

[12] 王玉莹, 沈春竹, 金晓斌, 鲍桂叶, 刘晶, 周寅康. 基于 MSPA 和 MCR 模型的江苏省生态网络构建与优化. 生态科学, 2019, 38(2)： $138-145$.

[13] 齐松, 罗志军, 陈瑶瑶, 赵杰, 林晓霞. 基于 MSPA 与最小路径方法的袁州区生态网络构建与优化. 农业现代化研究, 2020, 41 (2) : 351-360.

[14] 李欣鹏, 李锦生, 侯伟. 区域生态网络精细化空间模拟及廊道优化研究一一以汾河流域为例. 地理与地理信息科学, 2020, 36(5): 14$20,55-55$.

[15] 曹翊坤, 付梅臣, 谢苗苗, 高云, 姚思瑶. 基于 LSMM 与 MSPA 的深圳市绿色景观连通性研究. 生态学报, 2015, 35(2) : 526-536.

[16] Cai A L, Wang J, MacLachlan I, Zhu L K. Modeling the trade-offs between urban development and ecological process based on landscape multifunctionality and regional ecological networks. Journal of Environmental Planning and Management, 2020, 63( 13): 2357-2379.

[17] 彭建, 赵会娟, 刘炎序, 吴健生. 区域生态安全格局构建研究进展与展望. 地理研究, 2017, 36(3): 407-419.

[18］梁艳艳, 赵银娣. 基于景观分析的西安市生态网络构建与优化. 应用生态学报, 2020, 31(11): 3767-3776.

[19] 陈竹安, 况达, 危小建, 张立亭. 基于 MSPA 与 MCR 模型的余江县生态网络构建. 长江流域资源与环境, 2017, 26(8) : 1199-1207.

[20] Shen H, Zhang J, Yu B. Research on urban greenway system planning based on the promotion of ecological function: Taking Chengdu as the example. Boletin Tecnico/Technical Bulletin, 2017, 55(20): 90-97.

[21] 刘佳, 尹海伟, 孔繁花, 李沐寒. 基于电路理论的南京城市绿色基础设施格局优化. 生态学报, 2018, 38(12): 4363-4372.

[22] 荣月静, 严岩, 王辰星, 章文, 朱婕缘, 卢慧婷, 郑天晨. 基于生态系统服务供需的雄安新区生态网络构建与优化. 生态学报, 2020 , 40 (20) : 7197-7206.

[23] 郭家新, 胡振琪, 李海霞, 刘金兰, 张雪, 赖小君. 基于 MCR 模型的市域生态空间网络构建. 农业机械学报, 2021, 52(3): 275-284.

[24] 郑茜, 曾菊新, 罗静, 崔家兴, 孙璇. 武汉市生态网络空间结构及其空间管治研究. 经济地理, 2018, 38(9)：191-199.

[25] 田雨, 周宝同, 付伟, 王蓉. 2000-2015 年山地城市土地利用景观格局动态演变研究一一以重庆市渝北区为例. 长江流域资源与环境, $2019,28(6)$ : 1344-1353.

[26] 于亚平, 尹海伟, 孔繁花, 王晶晶, 徐文涁. 南京市绿色基础设施网络格局与连通性分析的尺度效应. 应用生态学报, 2016, 27(7)： 2119-2127.

[27] 董子燕, 张友水. 基于城市景观格局和连通性的地表温度贡献分析. 地理信息世界, 2020, 27(4): 75-82.

[28] Tortora A, Statuto D, Picuno P. Rural landscape planning through spatial modelling and image processing of historical maps. Land Use Policy, $2015,42: 71-82$.

[29] Xu H Y, Zhao G H, Fagerholm N, Primdahl J, Plieninger T. Participatory mapping of cultural ecosystem services for landscape corridor planning: A case study of the Silk Roads corridor in Zhangye, China. Journal of Environmental Management, 2020, 264: 1-10.

[30] Wood M A, Gilbert J A, Lacher T E Jr. Payments for environmental service's role in landscape connectivity. Environmental Conservation, 2020 , 47 (2) : 89-96.

[31] Viani R A G, Braga D P P, Ribeiro M C, Pereira P H, Brancalion P H S. Synergism between payments for water-related ecosystem services, ecological restoration, and landscape connectivity within the Atlantic forest hotspot. Tropical Conservation Science, 2018, 11:1-9.

[32] 吴敏. 城市绿地生态网络空间增效途径研究. 北京: 中国建筑工业出版社, 2016: 54-57.

[33] 杜志博, 李洪远, 孟伟庆. 天津滨海新区湿地景观连接度距离阈值研究. 生态学报, 2019, 39(17): 6534-6544.

[34] 汪金梅, 雷军成, 王莎, 吴婕, 梁屹, 陈永林, 熊星, 王军围. 东江源区陆域生态网络构建与评价. 生态学杂志, 2020, 39(9) : 3092-3098.

[35] 刘晓阳, 魏铭, 曾坚, 张森. 闽三角城市群生态网络分析与构建. 资源科学, 2021, 43(2): 357-367.

[36] 殷炳超, 何书言, 李艺, 李杨帆. 基于陆海统筹的海岸带城市群生态网络构建方法及应用研究. 生态学报, 2018, 38(12): 4373-4382.

[37] 何㑆, 林涛, 吴建芳, 随梦飞, 刘恋, 丁国昌. 基于空间优先级的福州市中心城区绿色基础设施网络构建. 应用生态学报, 2021, 32(4): 1424-1432.

[38] Wang H J, Zhang B, Liu Y L, Liu Y F, Xu S, Zhao Y T, Chen Y C, Hong S. Urban expansion patterns and their driving forces based on the center of gravity-GTWR model: a case study of the Beijing-Tianjin-Hebei urban agglomeration. Journal of Geographical Sciences, 2020, 30(2) : 297-318.

[39] 陈裕婵, 张正栋, 万露文, 张杰, 杨传训, 叶晨, 李青圃. 五华河流域非点源污染风险区和风险路径识别. 地理学报, 2018, 73(9)： 1765- 1777 . 